\title{
Influence of the third generation pill controversy on prescriptions for oral contraceptives among first time users: population based study
}

Lolkje de Jong-van den Berg, Hilde Tobi, Bert Bijker, Paul van den Berg

Department of Social Pharmacy, Pharmacoepidemiology and

Pharmacotherapy, Groningen

University Institute

for Drug

Exploration,

Antonius

Deusinglaan 2,

$9713 \mathrm{AV}$

Groningen,

Netherlands

Lolkje de Jong-van

den Berg

professor

Hilde Tobi

assistant professor

Bert Bijker

data analyst

Paul van den Berg

database manager

Correspondence to:

$\mathrm{L}$ de Jong-van den

Berg

jongltw@farm.rug.nl

BMJ 2003;326:254

\section{Participants, methods, and results}

We used pharmacy dispensing data from the InterAction database (a general prescription drugs database) in the northern Netherlands. In 2000, the database contained prescriptions from a population of approximately 37000 women aged 15-44, and 224 prescribers (general practitioners and outpatient specialists). We selected all prescriptions for oral contraceptives from 1 January 1994 to 31 December 2000. First time users of oral contraceptives were defined as women who, according to the database, either were prescribed any oral contraceptive for the first time or who had not been prescribed an oral contraceptive for at least one year. Hence, 1994 was used as a washout period. We calculated for first time users of oral contraceptives the proportion of women per year receiving a third generation oral contraceptive (1995 to 2000). To study a change in the proportion, we used SPSS version 10 to calculate $\chi^{2}$ tests for linear trend after stratification by age $(<20,20-24,25-29,30-34,35-39$, and $\geqslant 40$ years).
The prevalence of women aged 15-44 taking the pill was stable from 1995 to 2000 (around 54\%) (table). In 1995, the proportion of first time oral contraceptive users taking a third generation pill was $73 \%$ for the youngest age group (15-20 years) and 65\% for the women aged 20-24. For all other age groups, except for $30-34$, the proportions were also above $50 \%$, indicating that more than half of the first time users received a third generation oral contraceptive. In 1996, the first year after the pill scare, the proportions decreased to below $50 \%$ for all age groups. The change was most evident in women younger than 20; for these users the percentage of all first time users prescribed a third generation oral contraceptive decreased from $73 \%$ in 1995 to $11 \%$ in 2000 .

\section{Comment}

The number of women prescribed the third generation pill decreased dramatically after the pill scare in 1995; the decrease was most notable for women under 25 . The percentage of women prescribed a third generation oral contraceptive continued to decline over the following six years.

Contributors: LdJvdB and HT designed the study, analysed and interpreted the data, and wrote the manuscript. PvdB and BB managed the data and analysed the pharmacy data. LdJvdB is the guarantor.

Funding: None.

Competing interests: None declared.

1 Kemmerden JM, Algra A, Grobbee DE. Third generation oral contraceptives and risk of venous thrombosis: meta-analysis. BMJ 2001;323:131-4.

2 World Health Organization Collaborative Study of Cardiovascular Disease and Steroid Hormone Contraception. Venous thromboembolic disease and combined oral contraceptives: results of international mulidisease and combir Lancet 1995:346:1575-82.

3 De Vries CS, van den Berg PB, de Jong-van den Berg LTW. Oral contraceptive use before and after the latest pill scare in the Netherlands. Changes in oral contraceptive use and how users change. Contraception $1998 ; 57: 247-9$.

4 Geijer RMM. Onrust rond de pil, pleidooi voor een conservatief beleid [Scare around the pill, argument for a conservative policy]. Huisarts Wet 1996:39:110-2.

5 Drife JO. The third generation pill controversy ("continued"). BMJ 2001;323:119-20.

(Accepted 15 May 2002)

Proportion of women taking a third generation oral contraceptive among first time users of oral contraceptives. Results are numbers (percentage)

\begin{tabular}{|c|c|c|c|c|c|c|c|}
\hline & 1995 & 1996 & 1997 & 1998 & 1999 & 2000 & $\begin{array}{l}P \text { value for } \\
\text { linear trend }\end{array}$ \\
\hline $\begin{array}{l}\text { Women aged } 15-44 \text { taking } \\
\text { oral contraceptives }\end{array}$ & $14862 / 27522(54.0)$ & 15 914/29 579 (53.8) & 20 529/37 $393(54.9)$ & $20417 / 37810$ (54.0) & 20 201/37 548 (53.8) & 20 086/37 615 (53.4) & \\
\hline \multicolumn{8}{|l|}{ Age of first time users (years): } \\
\hline $15-20$ & $166 / 227(73)$ & $202 / 568(36)$ & $202 / 604(33)$ & $202 / 702(29)$ & $154 / 733(21)$ & $80 / 760(11)$ & $<0.001$ \\
\hline $20-24$ & 129/200 (65) & 104/237 (44) & $79 / 202(39)$ & $94 / 262(36)$ & $60 / 225(27)$ & $49 / 220(22)$ & $<0.001$ \\
\hline $25-29$ & $141 / 258(55)$ & $113 / 279(41)$ & $75 / 189(40)$ & $83 / 255(33)$ & $51 / 199(26)$ & $39 / 147(27)$ & $<0.001$ \\
\hline $30-34$ & 102/222 (46) & $85 / 261(33)$ & $68 / 217(31)$ & $78 / 229(34)$ & $55 / 196(28)$ & $54 / 163(33)$ & 0.006 \\
\hline $35-39$ & $71 / 138(51)$ & $61 / 182(34)$ & $37 / 150(25)$ & $50 / 210(24)$ & $55 / 193(28)$ & 28/153 (18) & $<0.001$ \\
\hline $40-44$ & $58 / 95(61)$ & $58 / 158(37)$ & $52 / 172(30)$ & $36 / 184(20)$ & $33 / 168(20)$ & $26 / 163(16)$ & $<0.001$ \\
\hline Total & $1140(59)$ & $1685(37)$ & $1534(33)$ & $1842(30)$ & $1714(24)$ & $1606(17)$ & $<0.001$ \\
\hline
\end{tabular}

